\author{
Marcin Golaszewski* \\ Dawid Ligocki*
}

\title{
„EIN SCHRIFTSTELLER, DER POLITISCHE GEGENSTÄNDE IN SEIN KÜNSTLERISCHES SCHAFFEN EINBEZIEHEN WILL, MUß AN DER POLITIK GELITTEN HABEN"6 KLAUS MANN UND DIE POLITIK. MEPHISTO - ROMAN EINER KARRIERE ODER KARRIERE EINES ROMANS ${ }^{1}$
}

Klaus Mann ist einer der ersten deutschen Schriftsteller, die den Entschluss fassten, das ,Dritte Reich' zu verlassen und ins Ausland zu gehen (vgl. Spangenberg 1984, S. 40). Er gehörte dann zu Autoren der „Stunde Null“ des Exils. ${ }^{2}$ Mag seine „Heimatlosigkeit" auch relativ früh aufgetreten sein, bedeutete sie doch das Ende eines Prozesses der Reifung, nicht nur der persönlichen, sondern zugleich auch der politischen. Und trotz des Exils oder sogar deswegen befasste sich Klaus Mann stets mit der politischen Situation in Deutschland und versuchte, eine Alternative für die entstehende und dann an die Macht kommende nationalsozialistische Bewegung zu schaffen, eine Art literarische Opposition im Ausland. In seinem literarischen wie privaten Leben ist ein deutlich sichtbarer politischer Prozess zu verzeichnen, der seine Vollendung nicht im Moment der Auswanderung, sondern erst im Exil findet.

Im vorliegenden Beitrag soll untersucht werden, wie sich die politischen Ansichten Klaus Manns vor und nach 1933 bis zur Entstehung seines bekanntesten Romans Mephisto entwickelt haben. Im Weiteren wird der ästhetische Einfluss skizziert, unter dem Klaus Mann stand. Dargestellt wird auch, wodurch die Entstehung des Romans Mephisto bedingt war. Des Weiteren soll auf den Roman selbst

* Dr. Marcin Gołaszewski, Lehrstuhl für Literatur und Kultur Deutschlands, Österreichs und der Schweiz, Universität Łódź, 90-236 Łódź, Pomorska 171/173 und Institut für Germanistik an der Adam-Mickiewicz-Universität Poznań im Rahmen des Forschungsprojektes FUGA des Polnischen Nationalen Forschungszentrums (NCN), 61-874 Poznań, al. Niepodległości 4.

*** Dawid Ligocki, Wissenschaftlicher Mitarbeiter an der Professur für Strafrecht, insbesondere Europäisches Strafrecht und Völkerstrafrecht, Juristische Fakultät, Europa-Universität Viadrina, 15-230 Frankfurt (Oder), Große Scharrnstr. 59.

${ }^{1}$ Die Publikation entstand dank finanzieller Unterstützung des Polnischen Nationalen Forschungszentrums (NCN). Vertragsnummer: 2013/08/S/HS2/00224.

${ }^{2}$ Klaus Mann emigrierte am 13. März 1933 nach Frankreich, nachdem seine Schwester Erika bereits einen Tag davor ausgewandert war. 
eingegangen werden, ohne aber den Inhalt nachzuerzählen, denn nicht der Inhalt sollte im Mittelpunkt stehen, sondern der Versuch, nachzuzeichnen, dass der Roman der Effekt einer langjährigen politischen Entwicklung Klaus Manns war. Vorwiegend wird darauf eingegangen, wie Mephisto im Moment seiner Premiere, die zugleich zu Beginn einer bisher in der deutschen Literaturwissenschaft einmaligen nicht nur einer literarischen, sondern auch einer gerichtlichen Karriere, wahrgenommen wurde und wie sich diese Wahrnehmung entwickelte. Es wird darauf verwiesen, dass bei Klaus Mann von früher Jugend an das Bedürfnis sehr ausgeprägt war, „Bekenntnisse und Geständnisse abzulegen, wie sehr er sich selbst zur Selbstbeobachtung, Selbstanalyse und Selbstdarstellung gedrängt fühlte" (Reich-Ranicki 1977, S. 269), die sich teilweise auch im Roman Mephisto widerspiegeln. Mephisto ist das beste Beispiel dafür, wie ein exilierter Schriftsteller zu den damaligen politischen und gesellschaftlichen Vorgängen in literarischer Form Stellung nahm und wie er sie auf die ihm als Literaten zugängliche Art zu verspotten versuchte.

Darüber hinaus soll im letzten Teil des Beitrags untersucht werden, wie die Nymphenburger Verlagshandlung mit ihrer Verfassungsbeschwerde gegen das Verbot des Romans scheiterte und welche Auswirkungen dies für den Literaturbetrieb in der bundesrepublikanischen Literaturlandschaft hatte. Es wird die Mephisto-Entscheidung des Bundesverfassungsgerichts vom 24. Februar 1971 diskutiert, in der sich das BVerfG mit dem Verhältnis zwischen Kunstfreiheit und anderen Grundrechten befasste.

\section{Klaus Manns politische Haltung}

Es heißt beides bestehen: die gefährliche Zeit, mit der wir alle fertig werden müßen, und das gefährliche Schicksal, mit dem nur gerade ich fertig zu werden habe (Mann 1986, S. 195).

1931 erscheint ein Essayband von Klaus Mann mit dem Titel Auf der Suche nach einem Weg, eine Sammlung von zeit- und literaturkritischen Stellungnahmen. Dieser Titel könnte stellvertretend für Klaus Manns Persönlichkeit in dieser Zeit stehen, denn er befindet sich auf der Suche nach dem eigenen Selbst und vor allem nach einer politischen Orientierung.

Er unterliegt vielfältigen Einflüssen, die sich überaus entscheidend für seine Entwicklung erweisen werden. Angefangen bei der Literatur, hauptsächlich bestehend aus „Repräsentanten einer vom Gefühl getragenen Weltanschauung der Dekadenz und der Morbidität" (Kerker 1977, S. 9), die sein irrationalistisches Weltbild in früher Jugend prägen, bis hin zu den politischen Ereignissen ist er unterschiedlichen Einflüssen ausgesetzt.

Seine Suche beginnt Klaus Mann als "schweifender Irrationalist" (Walter 1966), das Exil erlebt er schließlich als engagierter Schriftsteller.

Diese Entwicklung, vom politisch weitgehend desinteressierten Menschen hin zum verantwortungsbewussten Antifaschisten, wird in der Forschung häufig 
als Folge politischer Ereignisse, als eine Art von Zwang der Zeit, beschrieben. So heißt es hier unter anderem, dass ,,ihn der Umschwung der Zeit aus einem Ästheten zu einem Moralisten machte" (Kesten 1959, S. 415).

Tatsächlich muss es aber mehr sein als nur die Zeit, es ist das Ergebnis einer tiefgehenden Selbstauseinandersetzung. Einer Auseinandersetzung mit bisher geltenden Normen und Vorbildern, die davor noch einen bedeutenden Platz im Leben einnahmen, dann aber in Frage gestellt wurden.

Klaus Manns Generation ist vielfältig gespalten. Während des Ersten Weltkrieges aufgewachsen, mit dem „Gefühl, in einem Interim zwischen zwei Katastrophen zu leben" (Mann 1931, S. 33), kann sie ihm keine Richtung geben. Ebenso wenig die Generation der Väter, deren bürgerliche Werte für die Jugend keine Bedeutung mehr haben.

\section{Die politische Entwicklung bis 1933}

Ich aber glaubte lange bis zum Jahre 1933, um genau zu sein - daß das Politische sich gleichsam mit der linken Hand erledigen ließe, wie eine ,Fleißaufgabe'. Eher aus einem naiven Pflichtgefühl heraus als aus Ehrgeiz widmete ich meine ,Freizeit' den entscheidenden Problemen der Epoche (Mann 1984, S. 212).

Beeinflusst durch den Besuch der Bergschule Hochwaldhausen von April bis Juli 1922 und der Odenwaldschule von 1922 bis $1923^{3}$, entwickelt Klaus Mann ein Jugendgefühl, das er in Kind dieser Zeit rückblickend folgendermaßen beschreibt: „Der Geist der Jugendbewegung [...] hatte doch heftig dazu beigetragen, das Problematisch-Jugendliche in uns bewußt werden zu lassen, aufzuwühlen und gleichsam ins Programmatische zu stilisieren“" (Mann 1986, S. 133). Im Wendepunkt heißt es hierzu: „Man sagte: ,Ich bin jung!' und hatte eine Philosophie formuliert, einen Schlachtruf ausgestoßen. Jugend war eine Verschwörung, eine Provokation, ein Triumph (Mann 1984, S. 101).

Dieses positiv empfundene Jugendgefühl hinterlässt einen tiefen Eindruck auf den nach einer Gemeinschaft suchenden Klaus Mann. Er versucht es später zu übernehmen, indem er sich als Sprecher seiner Generation sieht, die ,über moralische Vorurteile ebenso erhaben ist wie über soziale Bindungen und politische Dogmen“" (Mann 1984, S. 162); Einer Generation, die während des Krieges aufgewachsen ist, „vielfältig gespalten und ohne einheitlichen Willen“ (Schiller 1983, S. 163), und eine ebenso chaotische Welt vorfindet.

${ }^{3}$ Beide Schulen sind „Gründungen der Landerziehungsheim-Bewegung. Unter dem Anspruch einer Reformpädagogik praktizierten diese Internate schon damals fortschrittliche Prinzipien wie Koedukation und Kurssystem mit Wahlfreiheit und gaben musischer wie praktisch-körperlicher Betätigung breiten Raum; die Schule wollte man als eine demokratische Gemeinschaft organisieren“ (Naumann 1984, S. 19). 
In Deutschland ist mit dem Ersten Weltkrieg und dem Ende des Kaiserreiches die alte Welt untergegangen. Die moralischen und ästhetischen Maßstäbe der bürgerlichen Gesellschaft zerfallen und haben für die Jugend keine Gültigkeit mehr, sie ,hatten in den Kriegs- und Revolutionsjahren ihre Autorität und Überzeugungskraft verloren“ (Mann 1984, S. 120). So entstand eine Generation, „die keinen gemeinsamen Weg, keine gemeinsame Richtung, keinen bindenden Stil besaß und darum nicht zueinander fand" (Strich 1960, S. 191).

Im Gegensatz zur französischen Jugend, bei der doch wenigstens ,das Suchen nach einem Ziel“" (Mann 1931, S. 23) verbindet, ist eine solche Gemeinschaft in Deutschland nicht möglich: „Aber die anderen wollten Klarheit, sogar die erträumte Gemeinschaft verbaten sie sich“ (ebd., S. 24). Für Klaus Mann war dies eine enttäuschende Erkenntnis; er versuchte, eine solche Gemeinschaft aufzubauen, indem er in den frühen Essays ${ }^{4}$ und Romanen die Probleme seiner Generation aufarbeitete. Im Vorwort von Der fromme Tanz beschreibt Klaus Mann sein Buch ,als eines, das aus unserer Jugend kommt, von unserer Jugend handelt, und nichts sein, nichts bedeuten möchte, als Ausdruck, Darstellung und Geständnisse dieser Jugend, ihrer Not, ihrer Verwirrung" (Mann 1989, S. 7).

Klaus Mann wird oft vorgeworfen, ihm ginge es in seinen Romanen nur darum, sich selbst zu repräsentieren. ${ }^{5}$ Dass dies aber nicht sein Ziel war, dass es ihm eher um die Herstellung eines Gemeinschaftsgefühls ging als um das Repräsentieren seiner selbst, verdeutlicht folgendes Zitat: „Vielleicht hatte der Beichtende schon vorher gewußt, wie alleine er war, vielleicht war solches ,Wir' nur eine erhoffte, gewollte, erträumte Form der Gemeinschaft, und er hatte sich keinen Augenblick eingebildet, ,repräsentativ“ zu reden“" (Mann 1931, S. 24).

Auf der Suche nach neuen Orientierungen entdeckt die gesamte Generation etwas, worin sie sich verwirklichen kann und Halt findet: sie besinnt sich auf den Körper, „den ,Leib, den elektrischen““(Mann 1984, S. 121). In Heute und Morgen schreibt Klaus Mann: „Ich sagte schon, was uns als einziges Erlebnis wirklich verbindet und überhaupt als Generation charakterisiert: es ist das neue Erlebnis des Körpers“ (Mann 1931, S. 33). Gleichzeitig findet sie in diesem zum Credo erhobenen Körperbewusstsein ihren ,stärksten Gegensatz zu der älteren Generation, der sie den Mangel allen Körpergefühls, die Überzüchtung der asketischen Moral und eines Geistes zum heftigsten Vorwurf machte“" (Strich 1960, S. 192).

${ }^{4} \mathrm{Zu}$ diesen Essays gehören: Fragment von der Jugend (1925), Heute und Morgen - Zur Situation des jungen geistigen Europas (1927), Zur Situation (1930). Alle sind enthalten in dem Band Auf der Suche nach einem Weg. Berlin 1931.

${ }^{5}$ Uwe Naumann verdeutlicht die Ansicht vieler Forscher und gibt auch die Situation zu Klaus Manns Zeit wieder, wenn er schreibt: „Daß er freilich die eigene Lebensweise mit der seiner ganzen Generation gleichsetzte, war naiv und ungehörig. Proletarische und kleinbürgerliche Jugendliche hatten im Deutschland der zwanziger Jahre ganz andere, oft existentielle Nöte, von denen das Dichterkind noch wenig wußte" (Naumann 1984, S. 29). 
Das Erotische hält sie zusammen, das eng mit dem Jugend- und dem Körpergefühl zusammenhängt, sowie die ,irrationale Strömung der Zeit“, der man sich „ganz und gar mit der Konsequenz" ergibt, asozial und politisch desinteressiert zu sein. Moral- und sozialpolitisch verantwortliche Werte zählen nicht. Man ist sich zwar bewusst, dass solche existieren, aber man hält sie strikt von sich weg, wie auch Klaus Mann bekennt: „In den politischen Fragen war ich Rationalist sogar damals, nur daß ich mich sowenig wie möglich mit ihnen auseinandersetzte“" (Mann 1986, S. 180).

Mitte der 1920er Jahre fühlt er sich nur als Künstler und Intellektueller, dies prägt sein Selbstbild, und so ,ist seine Haltung lange Zeit von einer Ablehnung jeder politischen Funktionssetzung in der Kunst bestimmt" (Schiller 1983, S. 169). Über seine Einstellung zu den beiden Komplexen: Künstlertum und soziale Verantwortung schreibt er im Wendepunkt:

Auf der einen Seite - so stelle ich gerne fest - haben wir die großen Mysterien des irdischen Daseins: Lust, Tod, Rausch, Einsamkeit, die unstillbaren Sehnsüchte, die schöpferischen ,Institutionen' [...] Auf der anderen Seite (und nun mußt du dein Gesicht in ernste Falten legen) haben wir unsere sozial-politische Verantwortung - eine verdrießliche Sache, aber nun einmal nicht aus der Welt zu schaffen.

Und weiter heißt es: „Wenn das leidige soziale Pensum erledigt ist, werden wir uns wieder mit unseren Ekstasen amüsieren dürfen“ (Mann 1984, S. 211). An diesem Zitat ist der Kernpunkt in der Entwicklung Manns besonders sichtbar; er unterscheidet deutlich zwischen Kunst und Politik, er trennt beide Bereiche strikt voneinander. Als Ästheten steht ihm der Irrationalismus sehr nahe, politisch ist er aber rationalistisch ausgerichtet, denn: „Die Politik ist das Gebiet, wo der Ratio vor dem Gefühl und der Ahnung der Primat gebührt“" (Mann 1931, S. 87f.).

Dies mutet auf den ersten Blick sehr widersprüchlich an, ist aber typisch für diese Entwicklungsphase Klaus Manns und durchaus folgerichtig: nur in einer Trennung von Kunst und Politik ist ihm der Hang zum Irrationalen möglich. Er steht damit „,vor dem gleichen Widerspruch wie die Väter: dem Verhältnis Geist-Tat"“ (Kerker 1974, S. 41).

Dieser Widerspruch entsteht aus der Bewunderung Klaus Manns für die irrationale Grundströmung der Zeit auf der einen Seite und dem politischen Bewusstsein auf der anderen. Gerade die Tatsache, dass beide Bereiche noch getrennt voneinander existieren, lässt Widersprüche entstehen: Geist-Tat, Leben-Vernunft oder auch Kunst-Politik.

Solche Widersprüche können nicht nebeneinander existieren, ohne in Konfrontation zu geraten. Es entsteht ein „Spannungsverhältnis der beiden jetzt noch getrennten Seiten“, in dem aber, und das ist entscheidend, die „künftige Entwicklung Klaus Manns angelegt“" (Naumann 1984, S. 44) ist. Nur mit Hilfe dieser Konfrontation kann er seinen künftigen Weg entdecken.

Auch Lutz Winckler erkennt in seinem Text Artist und Aktivist den außerordentlichen Einfluss des Irrationalen auf Klaus Mann, dass gerade hier der 
Ausgangspunkt für seine Entwicklung gebildet wird: „Denn das literarische Engagement entwickelt sich aus und in Auseinandersetzung mit spezifisch ästhetischen Traditionen“ (Winckler 1987, S. 74), er schreibt sich gerade aus der künstlerischen Verantwortung vor, ,nicht nur als Gebot der politischen Verantwortung des Schriftstellers" (ebd.).

Um dies deutlicher zu schildern, ist eine kurze Auseinandersetzung mit Klaus Manns literarischen Vorbildern nötig.

\section{3. Ästhetischer Einfluss - erster Schritt in der Auseinadersetzung mit dem Nationalsozialismus}

Beeinflusst wird Klaus Mann durch den Ästhetizismus des fin de siècle, eine Tradition, die sich soziologisch durch die Abgehobenheit der Kunst von der Lebenspraxis und ideologisch durch einen subversiven Antihumanismus kennzeichnet (vgl. ebd., S. 74).

In der Beschreibung der auf ihn wirkenden literarischen Einflüsse der Jahre 1920-1923 im 3. Kapitel Erziehung des Wendepunkts überwiegt das erotischreligiöse Element, während das soziale zurückbleibt: „Das Pantheon des Sechzehnjährigen bevorzugt eine Romantik, in der Ironie und Schwermut, Wollust und Frömmigkeit, metaphysische Ahnung und sexuell-emotionelle Ekstase einander begegnen und durchdringen“" (Mann 1984, S. 118).

Ein solch intensives Interesse schließt die Beschäftigung mit anderen Richtungen aus, zieht Einseitigkeit nach sich, und so heißt es an einer anderen Stelle: „Der Rationalismus findet sich kaum vertreten in meinem Knaben-Olymp“(ebd.). Klaus Mann sieht den Sinn der Kunst in ihr selbst. Nichts an einem Kunstwerk „weist über sich hinaus, nichts bedarf einer Erklärung, nichts will wirken außerhalb seiner selbst“" (Benn 1977, S. 217), wie der Nihilist und noch von Klaus Mann bewunderte Gottfried Benn betonte. Die Gegenbegriffe Tat, Vernunft und Politik treten in den Hintergrund, Literatur und Kunst sind unabhängig von jeglicher sozialer und politischer Verantwortung, da sie nichts bewirken können.

Dem entspricht dann auch der literarische ,Olymp', ein Kanon vorbildhafter Autoren, den Mann für sich entdeckt: Nietzsche, Hermann Bang und George: „Mein Olymp ist voll von Kranken und Sündern. Der wissensdurstige Knabe glaubte, von ihnen am meisten lernen zu können über die Geheimnisse der menschlichen Natur" (Mann 1984, S. 111).

Auf der Grundlage der Philosophie Bergsons definiert sich der Intellekt durch die Verständnislosigkeit für das Leben: „Hingabe an das Geheimnis, Hingabe an Bewegung und Fließen, nicht mehr Kritik“ (Mann 1931, S. 35). Für Mann bedeutet dies, wie er bekennt: „Das ästhetisch-literarische Interesse nahm mich so durchaus in Anspruch, daß mir für soziale Fragen jeder Sinn, jedes Verständnis fehlte" (Mann 1984, S. 83). 
Aber nicht nur die Auseinandersetzung mit literarischen Vorbildern ist entscheidend für seine Entwicklung hin zum politischen Engagement. Ein weiterer Aspekt wird im Zusammenhang mit dem Essay Heute und Morgen. Zur Situation des jungen geistigen Europas deutlich: es ist der politische Einfluss der Zeit, der Ende der 1920er Jahre entstehende Nationalismus und Militarismus in Deutschland, der schließlich dazu führte, die so nötige Verbindung von Kunst und Politik zu vollziehen.

Klaus Mann stellt hier einen Bezug zum Ersten Weltkrieg her, als sich die Intellektuellen politisch nicht engagierten. Der Geist ,erlag der Psychose, er machte mit, er verteidigte das Fürchterliche“. Daraus folgt für ihn die Frage, wie sich seine Generation angesichts eines drohenden Krieges verhalten würde, aber: „Wir $[\ldots]$ haben diese beinah unverzeihliche geistige Niederlage der väterlichen Generation als warnendes Beispiel“" (Mann 1931, S. 41).

Klaus Mann setzt diese Erkenntnis direkt für sich um, eine erste politische Orientierung wird daraufhin sichtbar: „Manche glauben ja sogar schon ein Ziel gefunden zu haben. Nationalismus und Militarismus haben größere Anziehungskraft denn je für die Jugend" (ebd., S. 25). Als Gegengewicht hierzu sucht er sein Ziel im ,europäischen Nationalismus', der die deutsch-nationale Strömung überwinden soll, wie er im Wendepunkt selbst schreibt: „Ich war gegen den Nationalismus - wie hätte ich nicht für Paneuropa sein sollen" (Mann 1984, S. 209), und wendet sich zunächst dem „Europäertum geistiger Liberalität zu“ (Kerker 1974, S. 41). Die Einheit Europas ohne den Herrschaftsanspruch eines einzelnen Landes ist für ihn das Ziel, und so wird er Anhänger des Grafen Richard Nikolaus von Coudenhove Kalergi, der 1923 in Wien die ,Paneuropa-Bewegung' gründete. Ziel dieser Bewegung war die Schaffung der, Vereinigten Staaten von Europa'.

Entscheidend für Klaus Mann ist wohl, dass dieses ,Paneuropakonzept" ihm eine Richtung gibt. Es bedeutet ihm viel, wie folgende Worte deutlich machen:

Immer noch keine Richtung? Immer noch kein Programm? Nach so vielen Fahrten immer noch kein Ziel? Doch: Ich versuchte, meiner Sehnsucht einen Namen zu geben, mein Erbe und meine Verpflichtung zu benennen. Europa! Diese drei Silben wurden mir zum Inbegriff des Schönen, Erstrebenswerten, zum inspirierenden Antrieb, zum politischen Glaubensbekenntnis und moralisch-geistigen Postulat (Mann 1984, S. 203).

Ein anderes wichtiges Moment in Bezug auf sein Ziel Paneuropas darf an dieser Stelle nicht vergessen werden, die Herstellung einer Gemeinschaft. Denn wenn er von den Erfahrungen seiner Generation spricht, wenn er deren Zerrissenheit deutlich macht, ist das gleichzeitig der Versuch, eine solche Uneinheitlichkeit zu überwinden. Er schreibt dazu: „Der eine war Nationalist, der andere Kommunist, der dritte melancholischer Ästhetizist, der vierte nichts als Erotomane. Warum entschloßen sich so wenige, Europäer zu sein, und im verpflichtendsten Sinn?!“ (Mann 1931, S. 47).

Er versucht, mit der Lösung Paneuropa seine Generation in dieser Aufgabe zu interpretieren, die sie verbände. Dabei steht „die Erfüllung eines kollektivistischen 
Traumes“ im Vordergrund; „er suchte seinem frühen Gemeinschaftserlebnis eine sinnvolle und fruchtbare Zukunft zu sichern" (Schneider 1956, S. 1108).

Wenn Klaus Mann in dieser Zeit von Europa spricht, so meint er im Grunde nur Deutschland und Frankreich. So schreibt er in Heute und Morgen, „daß jedes dieser beiden Länder ohne das andere verloren ist, daß es für Europa nur Rettung gibt, wenn diese beiden zusammengehen, Deutschland und Frankreich sind ja beinahe Europa" (Mann 1931, S. 24). Deshalb übernimmt er anfangs auch kritiklos das Konzept des Grafen Kalergi, nach dem England und die Sowjetunion ausgeschlossen werden sollten: „Hatte er nicht recht, Rußland, den halbmongolischen Koloß, aus seinem europäischen Zukunftsstaat zu verweisen. Und was England betraf, so war seine insulare Mentalität den ,guten Europäern' deutscher Zungen immer fremd und peinlich geblieben“ (Mann 1984, S. 209). Erst im Rückblick erkennt Klaus Mann seine politische Naivität in Bezug auf das politische Konzept von Paneuropa. Und dass es auch mit dem sozialen Fortschritt nicht so weit her ist, wie vom Grafen propagiert, erkennt er erst, als ihn die Bankiers und Industriellen zu ihrem Anführer machen: „Ein vereinigtes Europa, in dem technischer Fortschritt die soziale Befreiung garantiert und beide gesichert werden durch eine Herrschaft der Geistigen - das ist wohl die Formel, auf die Klaus Manns illusionäres Konzept einer europäischen Gemeinschaft zu bringen wäre" (Schiller 1983, S. 165). Illusionäres Konzept erkennt Klaus Mann erst später selbst und drückt seine Haltung rückblickend so aus:

Ich war verantwortungslos; ich war oberflächlich. Theoretisch begriff und betonte ich wohl die politische Verpflichtung des Literaten. [...] Statt mich aber mit den großen politischen und sozialen Fragen auf gründliche und nüchterne Art auseinanderzusetzen, begnügte ich mich, in meinen Reden und Manifesten, mit Anklagen und Forderungen recht unverbindlich allgemeiner Art (Mann 1984, S. 210).

Obwohl er schon versucht, sich politisch zu orientieren, drückt sich hier doch noch die "Spannung zwischen individueller Neigung und sozialer Tendenz" (Schneider 1956, S. 1108) aus. Klaus Mann betont die Einsicht in gewisse gesellschaftliche Erfordernisse und tut mit seiner Illusion eines vereinten Europas einen ersten Schritt in Richtung Politisierung, sein „Glaube an das Europäertum, an die geistige Sendung der Intellektuellen [...] bedeutet jedoch immer noch Flucht vor politischer Verantwortlichkeit" (Kerker 1974, S. 42).

Bei den Reichstagswahlen vom 14. September 1930 erhalten die Nationalsozialisten über sechs Millionen Stimmen und sind damit die zweitstärkste Partei. Im Vergleich zur Wahl vom 20. Mai 1928 haben sie ihren Anteil damit verachtfacht, die Zahl ihrer Mandate steigt von bisher 12 auf 107 (Vgl. Kühl 1987, S. 94f.).

In einem Vortrag für den deutschen Kulturbund in Wien im Herbst 1930 bezieht Klaus Mann hierzu öffentlich Stellung:

Wer in politicis bis gestern noch apathisch war, den hat das Resultat unserer Reichstagswahlen aufgerüttelt. Wenn sechs Millionen sich in aller Form zu einem Programm bekennen, das den Geist haßt [...] dürfen die Geistigen bei ihren metaphysischen Abstraktionen nicht länger verweilen (Mann 1931a, S. 95). 
Auch ihn rüttelt dieses Ergebnis auf, bewirkt in den folgenden Jahren bis 1933 die endgültige Revision seines Denkens. Praktisch umgesetzt bedeutet es eine Distanzierung vom Irrationalismus, und zwar ,genau zu dem Zeitpunkt, als er dessen mögliche Verbindungslinien und praktische Indienstnahme durch den Faschismus erkannte" (Winckler 1987, S. 73).

In dem Maße, wie die Nationalsozialisten an Stärke zunehmen, wird ihm auch sein Bekenntnis zum Irrationalismus als eine Gefahr bewusst - eigene Berührungspunkte werden sichtbar: „Aber wenn das ,Irrationale“ mir in seinen zärtlich-träumerischen, erotisch verbindenden Erscheinungsformen behagt hatte, so erschreckte es mich in seinen aggressiv brutalen Manifestationen, besonders wo diese den Charakter zerstörerischer Massenhysterie anzunehmen drohte" (Mann 1984, S. 250). Angesichts der politischen Entwicklung ist die ursprüngliche Trennung von Kunst und Politik nicht mehr möglich, denn das „Leben ist unteilbar, es läßt sich nicht in verschiedene ,Branchen“ mit beschränkter Verantwortung spalten. Was immer man tut, womit man sich auch beschäftigt - es ist der volle Einsatz, der gefordert wird" (ebd., S. 211).

Und je mehr sich die politische Lage zuspitzt, desto stärker wird die Neigung Klaus Manns, dem Künstler eine gesellschaftsbezogene Aufgabe zuzuordnen. Im „Rahmen der Gesellschaft habe der Schriftsteller im Namen der Vernunft zu sprechen“ (Grunewald 1985, S. 140), denn „die Vernunft ist des Lebens unentbehrlichste Dienerin. Ohne sie geht das Leben in Trümmer" (Mann 1931b, S. 87).

Klaus Mann geht mit seiner antisozialen Kunstprogrammatik, in der von einer verantwortungsbewussten Haltung des Schriftstellers überhaupt noch nicht die Rede ist, selbst ins Gericht. Er überwindet „,ie Antinomie [...], welche geistige Haltung und politisch-gesellschaftliche Realität voneinander" trennt, und ,grenzt sich gegen das Vergangene ab, gegen seinen Irrationalismus (Benn), gegen seinen Ästhetizismus (George), gegen die Haltung platonischen Gutseinwollens (Stefan Zweig), die politischen Notwendigkeiten Genüge tun will, ohne sich zu engagieren“ (Walter 1966).

Ausdruck dieser Abgrenzung ist die Auseinandersetzung mit Gottfried Benn, die 1930 mit dem Essay Zweifel an Gottfried Benn und der Kritik Gottfried Benn oder die Entwürdigung des Geistes fortgesetzt wird und 1937 in Gottfried Benn. Die Geschichte einer Verirrung ihr Ende findet (Mehr: Mann 1968).

Im ersten Text Zweifel an Gottfried Benn, der den eigentlichen Kernpunkt in der Auseinandersetzung bildet, bezieht sich Klaus Mann auf zwei Essays von Benn: Können Dichter die Welt verändern? und Zur Problematik des Dichterischen.

Benn vertritt in diesen Texten die Auffassung, dass für den Dichter die individuelle Vollendung im Mittelpunkt aller ethischen Kategorien steht, da Dichtung keinerlei Wirkung ausüben kann. Am Beispiel von Heinrich Manns Die kleine Stadt drückt er folgendes aus: „Kunstwerke sind phänomenal, historisch unwirksam, praktisch folgenlos. Das ist ihre Größe“ (Benn 1977, S. 215). Klaus Mann kann angesichts der Zeitumstände nicht einstimmen ,in das hymnisch exakte Preislied des genialen Benn, auf die Räusche der Einsamkeit“ (Mann 1968, 
S. 172). Er bekennt sich als Dichter zwar zu einer „manischen Neugierde“, die ihn in ,den verlockenden Abgrund dieser Dunkelheit zwingt" und fühlt sich angezogen von dessen „düster großartigen Theorie des absoluten Nihilismus“ (Ebd., S. 173), aber er erkennt die Forderung der Stunde, „die für keinen Dichter endgültige Ideale sein werden, aber eben doch für die Stunde die einzige möglichen“ (ebd., S. 174) - Frieden und Umgestaltung des Wirtschaftssystems.

Klaus Mann sieht sein Vorbild in Heinrich Mann, der „ein besonders repräsentatives Beispiel dafür [wäre], wie man künstlerische Vereinsamung, artistische Passion nicht nur mit politischer Gesinnung, sondern sogar mit schärfster politischer Aktivität vereinigen kann“ (ebd., S. 174). Er beantwortet die Frage Gottfried Benns, ob der Dichter die Welt verändern kann, mit: „Ja, ja, ja. Niemand kann sie verändern, wenn nicht er" (Mann 1931a, S. 111f.).

Den Brief an Gottfried Benn schreibt Klaus Mann bereits aus dem Exil, in dem er sich auch mit Gustaf Gründgens im Roman Mephisto auseinandersetzte. Er macht in dem Brief deutlich, wie beinah zwangsläufig die ästhetische Konzeption Benns mit dem Faschismus zusammenhängt, wie ,eine zu starke Sympathie mit dem Irrationalen zur politischen Reaktion führt, wenn man nicht höllisch genau achtgibt. [...] plötzlich ist man beim Kultus der Gewalt, und dann schon beim Adolf Hitler" (Mann 1968, S. 177).

Dieser Brief stellt dann auch den eigentlichen Bruch zwischen Klaus Mann und Gottfried Benn dar und ist der erste offenkundige Schritt in der polemischkritischen Auseinandersetzung mit der Wirklichkeit des nationalsozialistischen Staates, die im Mephisto-Roman mündete.

Anfangs ging es Klaus Mann noch ,um die Rettung des ,Dichters“, dessen Außenseiterposition - wo sie sich auf das ,Elementare‘ beruft und den Ursprung der Kunst im Mythisch-Irrationalen ansiedelt“" (Kerker 1977, S. 92) - auch seinem eigenen Kunstverständnis nahesteht. Das Engagement Benns für die Abschaffung des Paragraphen 218 lässt ihn für Klaus Mann sogar als einen radikal Linken erscheinen.

Als Benn dann aber ,selbst die politische Dimension seiner Literatur herstellt und die faschistische Politik“ (ebd.) positiv begrüßt, kann er das nicht mehr akzeptieren: „Das heimliche oder sogar lächelnd zugegebene Wohlgefallen, mit dem ein mir sonst verwandter und bewunderungswürdiger Geist wie Benn dies gräßliche Phänomen beobachtete und akzeptierte, konnte nicht umhin, mir auf die Nerven zu gehen. Ich fand mich genötigt, öffentlich gegen ihn Stellung zu nehmen [...] (Mann 1984, S. 250).

In Gottfried Benn oder die Entwürdigung des Geistes bezieht sich Klaus Mann auf Benns An die Emigranten. ${ }^{6}$ Er verurteilt hier scharf Benns Bekenntnisse zum

${ }^{6}$ Klaus Mann schreibt hierzu: „Die Aufklärung, um die ich ihn als Leser, als Bewunderer, fast als Freund, privat ersucht hatte, gab er mir in Form eines Offenen Briefes, ,An die Emigranten', den er im Rundfunk vorlas und der in der Deutschen Allgemeinen Zeitung publiziert wurde" (Mann 1968, S. 178). 
totalen Staat und seinen Verrat am Geist, der „uns sonst nur Ekel einflößen könnte, lehrt uns doch eines: Unversöhnbarkeit gegen die Verräter“ (Mann 1968, S. 181).

1937 erscheint der letzte Essay zu dieser Auseinandersetzung: Gottfried Benn. Die Geschichte einer Verirrung. Klaus Mann weist hier noch einmal auf den für ihn wichtigen Zusammenhang von Kunst und Fortschritt hin und er richtet sich ganz eminent gegen Benns Fortschrittsfeindlichkeit, für ihn gehören beide zusammen. Denn er erkennt die Gefahr, die sich gerade aus dem Irrationalismus und der Zivilisationskritik Benns ergibt: „Benn trieb die Flaubertsche Verachtung bourgeoiser Bildungs- und Fortschrittsgläubigkeit auf jene bedenkliche Spitze, wo sie in bösartigen Nihilismus umschlägt" (Mann 1984, S. 250), wo statt Form und Zivilisation, Ästhetizismus und Fortschritt, „Zucht und aristokratische Auswahl, Askese und Unterordnung“ im Mittelpunkt stehen. Im Gegensatz hierzu entwickelt Klaus Mann ein Konzept, in dem sich aus dem Willen zur Form der Wille zum Fortschritt entwickelt: „Als ,Ästhet' beginnen und als Sozialist enden: ich habe in solcher Entwicklungskurve ein Paradox niemals zu sehen vermocht. Das Schönheits-Pathos kann auf dem geraden Weg zum sozial-moralischen Pathos führen“ (Mann 1968, S. 189).

Klaus Mann beschreibt hier selbst seine politische Entwicklung, die sich aus der künstlerischen Verantwortung folgt. Mit dem Erfolg des Nationalsozialismus und der parallelen Entwicklung Benns erkennt Klaus Mann die Folgen seines Ästhetizismus. Denn gerade die ästhetische Tradition, die Sympathie mit dem Irrationalen, kann als politische Reaktion direkt in den Faschismus führen. Und der Schriftsteller, der mit seinem Wort Macht ausüben kann, trägt eine besondere Verantwortung: „Die ordinäre Hast, mit der so viele meiner Kollegen den Anschluß ans „Kommende', nämlich an die kommende Barbarei, suchten und fanden, erschien mir unschicklich bis zum Degoutanten. So benahm man sich nicht, wenn man sich dem Geist verpflichtet fühlte, wenn man Schriftsteller war“ (Mann 1984, S. 249).

Benns Position kann er nicht mehr akzeptieren. Klaus Mann steht für die Verbindung von Kunst und Politik und versucht, dem ,politischen Engagement des Antifaschismus eine ästhetische Begründung zu geben“(Winckler 1987, S. 76).

Genau hier folgt der Kernpunkt der Theorie Wincklers: „Aufhebung der Rollenteilung zwischen dem Artisten und Aktivisten, dem Schriftsteller und dem Antifaschisten rückt die Literatur selbst, die eigentliche literarische Tätigkeit also, in jene Position, die ihr von Klaus Mann zugedacht war: ins Zentrum antifaschistischen Engagements" (ebd.).

Und so ist Klaus Manns Weg ins Exil nicht, wie bei vielen anderen, „durch äußere Ereignisse, durch Bedrohung, durch Gefahr für Leib und Leben etwa, erzwungen worden“, er ist ,vielmehr die Konsequenz dieses geistigen Revisionsprozesses“" (Walter 1966).

Klaus Mann schreibt rückblickend über seine politische Haltung vor dem Exil: „Mein Irrtum war, daß ich mich an diese schicksalhaften Fragen - die politischen - wagte, ohne daß sie mir wirklich auf den Nägeln brannten, mir wirklich 
zum Teil des eigenen Lebens, des persönlichen Dramas wurden“ (Mann 1984, S. 211). Wie er selbst schreibt, ist diese trotz der Distanzierung vom Nationalsozialismus und Politisierung eher oberflächlich. Es handelt sich eher um theoretische Bekenntnisse, die erst die politischen Ereignisse in die Tat umsetzen: „Die politische Ebene, auf der sich Klaus Mann von 1927 bis 1933 bewegt, bleibt abstrakt und ohne praktische Handlungsanweisungen" (Kerker 1977, S. 103). Und deswegen fragt Klaus Mann, ob er berechtigt sei, sich über politische Ereignisse zu äußern, denn ,[w]ie sollte mein Beitrag überzeugend und wirkungsvoll sein? Er war nicht mit Leiden bezahlt"“ (Mann 1984, S. 212).

Aber Klaus Mann hat seinen politischen Weg gefunden, er sieht das Wort als Mittel zur Macht, zur Veränderung der Welt, und bekennt sich zur politischen Verantwortung des Schriftstellers. Zwei entscheidende Faktoren haben dazu beigetragen: Seine Auseinandersetzung mit dem Irrationalismus und die politischen Ereignisse in Deutschland. Ob er aber den eigenen inneren Konflikt, den die entgegengesetzten Faktoren Kunst und Politik in ihm auslösten, wirklich überwunden hat, wird erst seine Entwicklung im Exil zeigen. Äußerlich ist mit der Machtergreifung der Nationalsozialisten 1933 die Wende vollzogen. Klaus Mann geht ins Exil.

\section{Exil und die Entwicklung bis zur Entstehung des Romans Mephisto}

Bereits 1927 erkennt Klaus Mann in dem Essay Heute und Morgen: „Fallen wir also auf keinen Edelfaschismus herein, den irgendein Ästhetizismus als den dernier cri empfiehlt! Gehört das Jahr 1930 der militärischen Diktatur? Gut, so lebt unsereins um diese Zeit in der Verbannung - 1935, soviel ist sicher, hat man sich eines anderen besonnen“" (Mann 1931, S. 55). So entschlossen, wie Klaus Mann es hier prophezeit, handelt er 1933 dann auch. Denn er fühlt sich schon vor der Emigration nicht mehr wohl in Deutschland, ,war ein Fremder in Deutschland, noch ehe [er sich] endgültig von ihm trennte" (Mann 1984, S. 256). Er äußert sich darüber mit sehr deutlichen und emotional beladenen Worten: „Ein Entwurzelter? Niemals war ich es so sehr wie damals, in einem schon fremd gewordenen Vaterland, dessen vergiftete Atmosphäre meine Stimme erstickte, ihr jede Resonanz und Wirkung nahm“" (Ebd., S. 264).

Die erste Zeit nach der Ernennung Hitlers zum Reichskanzler am 30. Januar 1933 verbringt Klaus Mann zunächst noch in Deutschland. Als er von einer Reise in die Schweiz am 10. März nach München zurückkehrt, erkennt er sofort: „München war besiegt, war gleichgeschaltet, wir spürten es, rochen es, sowie wir am Hauptbahnhof aus unserem Schweizer Zug stiegen“" (Ebd., S. 285). Drei Tage später, am 13. März 1933, verlässt er Deutschland. Besonders deutlich äußert sich über den Moment des Exils seines ältesten Sohnes Thomas Mann: „Sie endete, diese spielerisch-übermütige und begabte Kindheit, eigentlich erst mit dem Exil. Dieses machte ihn zum Mann; die Erfahrung des Bösen rief seinen Ernst auf" (Mann 1950, S. 8). 
Die Entscheidung, am 13. März 1933 ins Exil zu gehen (Mehr dazu: Pasche 2000, S. 38), ist die praktische Konsequenz seiner Entwicklung, die er bis 1933 gemacht hat, nicht die einer Bedrohung durch die Nationalsozialisten, die Möglichkeit eines Arrangements hätte wohl bestanden: „Meine ,rassische Erbmasse“ war zwar keineswegs einwandfrei, aber doch nicht verderbt genug, um mich im ,Dritten Reich“ völlig unmöglich zu machen“ (Ebd., S. 290). Es ist also hauptsächlich „ein Akt der Selbstverwirklichung“ (Kerker 1974, S. 107), eine im Innersten getroffene Entscheidung. Die Frage, ob man Hitler nicht in Deutschland hätte bekämpfen können, stellt sich Klaus Mann auch, aber es wäre die Wahl „zwischen sinnlosem Martyrium und opportunistischem Verrat“ gewesen; man war zu ,exponiert, um in der Masse zu ,verschwinden'; politisch zu sehr abgestempelt, um feine Indifferenzen vorzutäuschen“ (Mann 1984, S. 291), und: „Der Ekel hätte uns getötet, der Ekel an der eigenen Erbärmlichkeit und an dem widrigen Treiben um uns herum" (Ebd., S. 290). Für ihn ist es eine Konsequenz, die er nicht zu bereuen braucht:

Man hat sich oft geirrt im Leben, hat mancherlei zu bereuen. Dies eine hat man richtig gemacht, aus Instinkt mehr denn aus, Überzeugung': Warum sollte man nicht dafür dankbar sein? Die Emigration war nicht gut. Das Dritte Reich war schlimmer (Mann 1984, S. 291).

Klaus Mann definiert seine Funktion als deutscher Schriftsteller im Exil ,als eine doppelte“. Zum einen geht es ihm darum, „die Welt vor dem ,Dritten Reich“ zu warnen und über den wahren Charakter des Regimes aufzuklären“; zum anderen soll „die große Tradition des deutschen Geistes und der deutschen Sprache [...] in der Fremde lebendig“ erhalten ,und durch den eigenen schöpferischen Beitrag" (Mann 1984, S. 407) weiterentwickelt werden. Er unterscheidet hier selbst zwischen politischer und kultureller Aufgabe: „Es war nicht leicht, diese beiden Verpflichtungen [...] miteinander zu vereinigen“ (Mann 1984, S. 293).

In der Forschung wird der Beginn des Exils als eine damit abgeschlossene Entwicklung dargestellt, war es ,jedoch eher ein bleibendes Spannungsverhältnis, auch im Exil. Klaus Mann lebte ständig in dem Widerspruch zwischen zwei Polen“" (Naumann 1984, S. 235), denn mit dem Exil blieb der innere Konflikt zwischen Kunst und Politik, zwischen seiner ästhetischen Neigung und seiner sozial-politischen Verantwortung weiter bestehen. Klaus Mann engagiert sich praktisch vom ersten Tag seines Exils an für den antifaschistischen Kampf. In zahlreichen Reden, Essays und Artikeln nimmt er Stellung zur politischen Entwicklung in Deutschland und gründet bereits im September 1933 die Exilzeitschrift Die Sammlung (Mehr dazu: Weil 1983, S. 32-41), die im Amsterdamer Querido Verlag erscheint. So wird „der Antifaschismus der bestimmende Antrieb seiner Arbeit“ (Kerker 1974, S. 86).

Mit der Sammlung versucht Klaus Mann,

die Talente der Emigration beim europäischen Publikum einzuführen, gleichzeitig aber die Emigration mit den geistigen Strömungen in ihren Gastländern vertraut zu machen. Dazu kam, als essentielles Element meines redaktionellen Programms, das Politisch-Polemische. ,Die Sammlung' war schöngeistig, dabei aber militant. [...] Die Tendenz war gegen die Nazis (Mann 1984, S. 297f.). 
Dieses Zitat macht deutlich, welche Aufgabe Klaus Mann der Literatur gibt. Sie ist für ihn ein Instrument politischer Kritik. Angesichts seines Kampfes ist die ,reine Literatur nicht mehr möglich, die Politik muss stets miteinbezogen werden. Dementsprechend stellt Die Sammlung eine direkte Verbindung von, Geist" und ,Politik ${ }^{\text {‘ }}$ dar, und Klaus Mann erfüllt damit die ihm anfangs gestellte Aufgabe als Schriftsteller im Exil. Die Sammlung stellt gleichzeitig den Versuch dar, die Emigrierten im Kampf gegen Hitler zu vereinigen. Seiner Meinung nach können diese nur dann etwas erreichen, wenn sie es gemeinsam tun, „wenn über alle ideologischen Barrieren hinweg alle intellektuellen Kräfte zusammenwirken“"(Laemmle 1989, S. 205). Nach dem Paneuropa-Konzept lässt sich hier erneut der Versuch feststellen, zur Erfüllung eines politischen Programms eine Gemeinschaft aufzubauen. Diese von ihm angestrebte Vereinigung bildet die Grundlage für seine Bemühungen in dieser Hinsicht. Er ist sogar bereit, seine eigene Individualität diesem Ziel unterzuordnen, sich selbst in diesem Kampf zurückzustellen, und dies ,auch mit seinem dichterischen Werk“ (Schiller 1983, S. 171). Das Exil lenkt ihn endgültig weg vom Irrationalismus und hin zum Sozialen und Politischen (vgl. Weil 1983, S. 26).

Fast alle seine Exilwerke, zumindest die größten, erheben politischen Anspruch; sein Hauptwerk Der Vulkan handelt direkt vom Exil, sein berühmtester Roman Mephisto spielt im faschistischen Deutschland. Dass es aber außerordentlich schwierig für ihn ist, sich seinem politischen Anspruch ganz zu unterwerfen, zeigt, dass doch immer wieder Werke entstehen, die rein künstlerischer Natur sind. Symphonie Pathetique entsteht nach dem Roman Flucht in den Norden, der sich ausschließlich mit der Exilproblematik befasst. Vergittertes Fenster folgt direkt auf Mephisto.

\section{Mephisto - Roman einer Karriere oder Karriere eines Romans?}

Wenn Peter Laemmle im Nachwort zum Tagebuchband der Jahre 1936-1937 bemerkt, dass alles, „was Klaus Mann in diesen zwei Jahren schreibt“, der Versuch ist, „den eigenen Standpunkt zu bestimmen, im persönlichen, ästhetischen, politisch-intellektuellen Bereich“"(Laemmle 1990, S. 187), so ist das zwar richtig, macht aber gleichzeitig Klaus Manns Widersprüchlichkeit deutlich. Eine Standpunktbestimmung ist nie eindeutig bei ihm, es ist fast immer das Bekenntnis zu unterschiedlichen Positionen, ja fast zu Gegensätzlichkeiten. Eine politische Stellungnahme und Abrechnung mit Deutschland im Mephisto steht neben der ästhetischen Auseinandersetzung in der Erzählung Vergittertes Fenster, in der persönliche Problematik, wie Homosexualität, Todessehnsucht und das Verhältnis zur ehemaligen Heimat Bayern behandelt werden.

Mephisto nimmt daher eine der zentralen Positionen im literarischen, politisch orientierten Schaffen Klaus Manns ein und ist dementsprechend im Ausdruck und in Bezug auf konkrete Personen und Fakten am deutlichsten. Der Roman erscheint im Jahr 1936 mit der Bemerkung des Autors: „Alle Personen dieses Buches stellen 
Typen dar, nicht Porträts“ (Mann 1973, S. 344). Dies war nötig, weil die Biographie des Ex-Schwagers, Gustaf Gründgens, als Vorlage für die Figur des Hauptprotagonisten diente. Dass die Pariser Tageszeitung das Recht der Erstveröffentlichung erworben hatte, hat sie noch vor dem Erscheinen des Romans für ein besonderes Interesse gesorgt, indem sie Mephisto als einen Schlüsselroman bezeichnete: „Ein Schlüsselroman. Das neue Werk von Klaus Mann, mit dessen Veröffentlichung die ,Pariser Tageszeitung' am Sonntag beginnt, ist ein Theaterroman aus dem ,Dritten Reich'. Im Mittelpunkt steht die Figur eines Intendanten und braunen Staatsrats, der die Züge Gustaf Gründgens' trägt" (Zit. nach Landshoff 1991, S. 258). Da Klaus Mann sofort darauf reagierte und die Tageszeitung aufforderte, dies zu dementieren, erschien in der nächsten Ausgabe eine kurze Zusammenfassung seines Telegramms: „Mein Roman ist kein Schlüsselroman. Held des Romans erfundene Figur ohne Zusammenhang mit bestimmter Person. Klaus Mann“ (Zit. nach Spangenberg 1984, S. 91). Nichtsdestotrotz ist an dieser Stelle zu betonen, dass die Ähnlichkeiten nicht nur zwischen Höfgen und Gründgens, sondern zwischen mehreren Protagonisten und realen Personen unübersehbar sind. Deswegen kann man nach Fredric Kroll (1973) diesen Roman mit Recht als einen „biographischen Roman“(S. 191) bezeichnen.7 Das war auch der Grund, warum Mephisto. Roman einer Karriere bereits vor dem Erscheinen seine eigene Karriere startete, die letzten Endes im Verfahren vor dem Bundesverfassungsgericht endete. Denn Klaus Mann bemühte sich nach dem Zweiten Weltkrieg, „eine Neuauflage des Mephisto in einem deutschen Verlag zu erwirken“" (Maltzan 2001, S. 17). Dies gelang aber weder ihm noch Erika Mann, seiner Nachlassverwalterin. Erst 1965 wurde der Roman in der Bundesrepublik neu aufgelegt, nachdem Mephisto in der DDR erschienen war. Doch kaum ein halbes Jahr später erwirkte der Adoptivsohn Gustaf Gründgens', Peter Gorski-Gründgens, ein Verbot des Romans.

1936, das Erscheinungsdatum des Romans, ist als Wendepunkt für die Exilanten anzusehen, die erst dann haben verstehen müssen, das ,Dritte Reich“ sei keine kurzdauernde Epoche deutscher Geschichte: „Mephisto steht deutlich im Schnittpunkt dieser Bewußtseinsveränderung. Das Gewicht, das der Autor besonders im Finale der Fabel dem Kampf der Illegalen einräumt, rührt noch aus der ersten Periode des Exils, die Schärfe des Urteils über den Mitläufer Höfgen hingegen entstammt der neuen Sicht" (Walter 1965).

Der Roman präsentiert den Aufstieg, die kolossale Karriere des begabten Schauspielers Hendrik Höfgen, der, ,trotz mancher Divergenzen mit seinen faschistischen Dienstherren, zur gefeierten Symbolfigur des ,Dritten Reiches' avanciert" (Schmidt 2003, S. 24). In Mephisto wird exemplarisch die Geschichte eines Mannes dargestellt, „der zum [...] Mitläufer“ (Winckler 1984, S. 54) des Nationalsozialismus wird, wobei die Geschichte keine ausgedachte, sondern eine durchaus auf Personen und Fakten bezogene ist. Besonders deutlich äußert sich Hans-Albert Walter (1965) über Höfgen, der ,gewissermaßen eine Hure jeglicher öffentlichen

\footnotetext{
${ }^{7}$ Eine komplette Liste der dekodierten Personen aus dem Roman: (vgl. Weil 1983, S. 70-71).
} 
Meinung“ sei und Everett Falconer Harrison (1966) behauptet, er sei „the very incarnation of evil"“ (S. 240). Im Mephisto wird Höfgen als „ein Affe der Macht und ein Clown zur Zerstreuung der Menschen“ (Mann 1973, S. 204) beschrieben. Klaus Mann geht es aber in erster Linie nicht nur darum, einen einzigen typischen Fall zu schildern, sondern er stellt dar, wie man sich unter dem Druck einer Diktatur verhalten konnte. Im Wendepunkt erklärt er deutlich, was er mit dem Roman erreichen wollte und warum er die Person Gründgens als Höfgen entlarvt. Die Hauptfigur soll zum ästhetischen Medium werden, in dem sich all das verkörpert, was zur Enthüllung des faschistischen Systems als ,eines durchaus komödiantischen, zutiefst unwahren, unwirklichen Regimes" nötig war (Mann 1984, S. 357). Deswegen versetzt Klaus Mann die Handlung des Romans in die Theater- und Kulturszene, die er aus der Berliner Zeit sehr gut kannte, und am Beispiel einzelner Protagonisten schildert er unterschiedliche Varianten des Konformismus im „Dritten Reich“. Dabei greift er die Gruppe der „bewußten Mitläufer“ heraus, die „charakterliche Schwäche und hellsichtigen Intellekt" (Walter 1966, S. 445) haben. Darüber waren aber nicht alle Zeitgenossen Klaus Manns einig, denn Lion Feuchtwanger sprach im Kontext der Entstehung des Romans von persönlichen Beweggründen und sogar von ,schöpferischem Haß“: „Das Buch ist mit Haß geschrieben, aber es ist ein Haß, welcher den dargestellten Menschen und Dingen Dichtigkeit gibt. Haltbarkeit, eine faszinierende Überwirklichkeit. Der Schauspieler Höfgen ist mehr als ein beliebiger Schauspieler, der sich gegen seinen Geschmack und gegen seine Überzeugung einem schädlichen, abscheulichen Regime verkauft, er wird zum Symbol der Eitelkeit und des Arrivismus überhaupt, es ist eine Molieresche Gestalt, lebend von dem schöpferischen Haß des Autors" (Feuchtwanger 1950, S. 58). Ähnlich sieht dies Anke-Marie Lohmeier (1987), wenn sie behauptet, Klaus Mann gehe es im Roman um eine Art Rache an seinem Ex-Schwager; Mephisto sei Resultat von ,seiner Enttäuschung und Erbitterung, ja seinem Haß auf den ehemaligen Schwager" (S. 102). Auch Thomas Mann äußert sich über die allzu sehr auffallende Nähe des Romans zur Realität kritisch: „Die Beobachtung kann man ja machen, daß ein so sehr an die Wirklichkeit gebundenes Werk am gefährdetsten ist und gewissermaßen ratlos wird, wo es frei von ihr abweichen und sie verleugnen möchte. Da ist dann leicht nicht alles in Ordnung, manches ist mehr unrichtig als frei und manches sogar nicht recht - so kommt es uns vor (Mann 1991, S. 273). Und es mag stimmen, dass Klaus Mann den Roman teilweise aus Rache auf Gustaf Gründgens schrieb, denn dies bestätigt Kadidja Wedekind in ihrem Brief an Frederic Kroll vom 20. Dezember 1978, indem sie sich an ihr Gespräch mit Klaus Mann erinnert: „Ich sagte: Du schriebst das Buch, um Gustaf ins Konzentrationslager zu bringen und das tut man einem früheren Freund nicht an. - Und Klaus gab zu, daß er das Buch zum Teil zu diesem Zweck schrieb“ (Zit. nach Kroll 1991, S. 219).

Dass Klaus Mann gerade auf die Theaterszene zurückgreift, ist nicht nur biographisch zu begründen. Er erklärt die auffallende Ähnlichkeit zwischen dem Verhalten der Nazis und der Schauspieler: „Sollten wirklich unüberwindbare 
Gegensätze bestehen zwischen diesen Komödianten, die wirkliche Verbrechen begingen, und dem anderen, der die Verbrechen nur spielte? Gehörten sie nicht im Grunde zu einer Familie?" (zit. nach Winckler 1983, S. 328). In ähnlicher Weise schildert dies auch Bertolt Brecht: „Es ist da kein Zweifel möglich, daß die Faschisten sich ganz besonders theatralisch benehmen. Sie haben besonderen Sinn dafür. Sie sprechen selber von Regie, und sie haben einen ganzen Haufen von Effekten, direkt aus dem Theater geholt: die Scheinwerfer und die Begleitmusik, die Chöre und die Überraschungen" (Brecht 1967, S. 560).

In dieser Nähe zwischen Kunst und Ideologie, zwischen Künstler und Nationalsozialisten sieht Klaus Mann eine Art ,Teufelspakt ${ }^{6}$. Arwed Schmidt (2003) sieht hier ganz richtig: „Diesem Pakt liegt eine tiefe Wesensverwandtschaft zugrunde: zu Höfgens komödiantischer Begabung, sich chamäleonartig zu assimilieren, und zur Beschaffenheit des braunen Herrschaftssystems, das die Realität durch eine Welt der Imitation, des Scheins und der Täuschung ersetzt, gehören essentiell Identitätsverleugnung und Rollenspiel“" (S. 25).

Gleich nach dem Erscheinen des Romans entbrannte eine lebhafte Diskussion unter den Kritikern, die sofort nach den realen Vorbildern hinter den Romanprotagonisten suchten und die Frage aufwarfen, ob Klaus Mann berechtigt war, dem Roman den Nachsatz hinzuzufügen, es handele sich um Typen und nicht um Porträts. Diese Diskussion, ganz abgesehen von der positiven oder negativen Beurteilung der literarischen Qualitäten des Werkes, durchzieht sich bis in die unmittelbare Nachkriegszeit bis der Roman vom Bundesverfassungsgericht verboten wurde (mehr zur Rezeption des Romans: Spangenberg 1984, S. 97-114).

\section{Mephisto-Beschluss des Bundesverfassungsgerichts}

Wenn im vorstehenden Abschnitt davon die Rede ist, dass die Karriere des Mephisto-Romans vor dem BVerfG ,endete“, so wäre diese Formulierung - wollte man sie wörtlich nehmen - aus juristischer Sichtweise alles andere als zutreffend. Denn das Verfahren vor dem BVerfG brachte mit dem Mephisto-Beschluss des Ersten Senats vom 24. Februar 1971 - 1 BvR 435/68 - ein Judikat (BVerfGE 30, 173) hervor, dessen Bedeutung für die Grundrechtsdogmatik, und insbesondere für das Verhältnis zwischen Kunstfreiheit und Allgemeinem Persönlichkeitsrecht, auch heutzutage - jahrelang nach dessen Erlass - nicht zu unterschätzen ist. An dieser Stelle ist darauf hinzuweisen, dass die Entscheidung keineswegs einstimmig, sondern mit einem Stimmenverhältnis von $4 \mathrm{zu} 2$ ergangen ist.

Bei dem Mephisto-Beschluss handelt es sich um eine Entscheidung, in der sich das BVerfG zum ersten Mal umfassend zum Verständnis der Kunstfreiheitsgarantie positionierte (Hufen 2011, § 101 Rdnr. 31).

Im Folgenden sollen die Kernaussagen der Entscheidung dargestellt werden. Dabei wird immer wieder auf literarische Aspekte Bezug genommen werden. Einer Erörterung wird auch die abweichende Meinung des Richters Stein zugeführt werden. 
Das BVerfG hatte sich mit der Frage auseinanderzusetzen, ob dem Verbot, den Roman zu vervielfältigen, zu vertreiben und zu veröffentlichen, die Kunstfreiheitsgarantie entgegenstand. Dieses Grundrecht ist in Art. 5 Abs. 3 Satz 1 GG verankert. Seine bescheidene Regelung lautet: „Kunst und Wissenschaft, Forschung und Lehre sind frei“". Neben einer objektiven, wertentscheidenden Grundsatznorm enthält diese Bestimmung ein ,individuelles Freiheitsrecht“ (BVerfGE 30, 173, 188). Sie erlaubt jedem, sich im Bereich der Kunst zu betätigen, und rechtswidrige staatliche Eingriffe abzuwehren (Sachs 2003, S. 308 Rdnr. 72). Die rechtliche Würdigung des Verbots der Veröffentlichung des Romans am Maßstab der Kunstfreiheit setzt zunächst voraus, dass die begehrte Veröffentlichung des Romans in den sachlichen Schutzbereich des Art. 5 Abs. 3 GG fällt, es sich dabei also thematisch um „Kunst“ handelt. Der Adoptivsohn Gründgens sprach dem Roman die Qualität eines Kunstwerks ab, indem er behauptete, ,[er sei] ein Schlüsselroman, in dem sich Klaus Mann an Gründgens räche, weil er die Ehre seiner Schwester Erika durch die Heirat mit Gründgens verletzt geglaubt habe“ (BVerfGE 30, 173, 177). Indessen erhoben die Gerichte keine Zweifel daran, dass der Roman ein Kunstwerk war und daher den Schutz des Art. 5 Abs. 3 GG genoss (BVerfGE 30, 173, 178). Das BVerfG nahm dennoch eingehend zur Begriffsbestimmung der Kunst Stellung. In der Entscheidung heißt es hierzu:

Das Wesentliche der künstlerischen Betätigung ist die freie schöpferische Gestaltung, in der Eindrücke, Erfahrungen, Erlebnisse des Künstlers durch das Medium einer bestimmten Formensprache zu unmittelbarer Anschauung gebracht werden. (...) [E]s ist primär nicht Mitteilung, sondern Ausdruck und zwar unmittelbarster Ausdruck der individuellen Persönlichkeit des Künstlers (BVerfGE 30, 173, 188 f.).

Weiterhin wurde dargelegt, die Kunstfreiheit gewährleiste nicht nur das Recht des künstlerischen Schaffens (sog. Werkbereich), sondern auch das Recht, das Geschaffene als Ergebnis der künstlerischen Betätigung darzubieten und zu verbreiten (sog. Wirkbereich), denn eine Beschränkung der Kunstfreiheit auf das forum internum würde dazu führen, dass die Kunstfreiheitsgarantie leerliefe (BVerfGE 30, 173, 189). Dieses Verständnis stützte das BVerfG bekräftigend auf die Erfahrung aus der Zeit des nationalsozialistischen Regimes und dessen „Kunstpolitik“ (BVerfGE 30, 173, 189). Ferner erstreckte das BVerfG die Reichweite der Verbürgung der Kunstfreiheit über die Person des Künstlers hinaus auf diejenigen, die eine ,vermittelnde Tätigkeit ausüben“ (BVerfGE 30, 173, 191). Insofern kann auch der Verleger aufgrund seiner ,unentbehrlichen Mittlerfunktion“"von Art. 5 Abs. 3 GG Gebrauch machen.

Der Annahme, es handele sich bei dem Roman um ein Kunstwerk, steht nicht im Wege, dass „der Künstler Vorgänge des realen Lebens schildert“ (BVerfGE 30, 173, 190). Denn ,die Realität [wird] aus den Zusammenhängen und GesetzmäBigkeiten der empirisch-geschichtlichen Wirklichkeit gelöst und in neue Beziehungen gebracht (...)“ (BVerfGE 30, 173, 190). Die Kunstfreiheit soll „die auf 
der Eigengesetzlichkeit der Kunst beruhenden (...) Entscheidungen von jeglicher Ingerenz öffentlicher Gewalt freihalten" (BVerfGE 30, 173, 190). Daraus folgt, dass der Inhalt des Romans und seine Bezüge zur Wirklichkeit und zu realen Personen diesen nicht um den Charakter eines unter den Schutz des Art. 5 Abs. 3 GG fallenden Kunstwerks bringen können. Der Staat kann ferner nicht zwischen „wertvoller“ und „wertloser" Kunst unterscheiden und letzterer den Schutz der Kunstfreiheit versagen; andernfalls könnte er den Schutzbereich dieses Grundrechts beliebig regeln und dessen Funktion als „Abwehrrecht" gegen den Staat unterlaufen (Isensee 1993, 619, 621). Solchen „qualitativen Bewertungen“ ist der Gewährleistungsbereich der Kunstfreiheit daher nicht zugänglich (Hufen 2011, $\S 101$ Rdnr. 54). Man spricht in diesem Zusammenhang vom Verbot „staatlichen Kunstrichtertums“" (Scholz 2014, Art. 5. Abs. 3 Rdnr. 25).

Das punctum saliens der Entscheidung betrifft die Frage der verfassungsmäßigen Rechtfertigung des Verbots, den Roman zu veröffentlichen. Die Lektüre des Wortlauts des Art. 5 Abs. 3 GG führt zu der Beobachtung, dass dieses Grundrecht absolut, d.h. vorbehaltlos, gewährleistet wäre. Es findet sich dort kein Hinweis darauf, dass die Kunstfreiheit in bestimmten Fällen, etwa wenn durch ihre Ausübung das Eigentum anderer verletzt wird, eingeschränkt werden darf. Nichtsdestoweniger ist eine verfassungsmäßige Rechtfertigung eines Eingriffs in die Kunstfreiheit möglich, denn diese Verbürgung kann „nicht schrankenlos gewährt" sein (BVerfGE 30, 173, 193). Die Grenzen der Kunstfreiheit dürfen allerdings nur von der Verfassung selbst vorgegeben sein (BVerfGE 30, 173, 193). Dies bedeutet, dass die Kunstfreiheit dann an ihre Grenzen stößt, wenn sie mit anderen verfassungsrechtlich verbürgten Rechten, beispielsweise Grundrechten Dritter, in Kollision gerät. In der juristischen Terminologie spricht man von ,verfassungsimmanenten Schranken“, also Beschränkungen eines Grundrechts, die sich aus kollidierendem (entgegenstehendem) Verfassungsrecht ergeben (Manssen 2015, § 8 Rdnrn. 152 f.; Scholz 2014, Art. 5 Abs. 3 Rdnr. 57). Im MephistoFall liegt folgendes Dilemma vor: Der Roman weist erhebliche Parallelen zur realen Welt auf. Insbesondere ist die Ähnlichkeit des Hauptprotagonisten Höfgens mit dem Schauspieler Gründgens nicht zu verkennen. Insofern entfaltet das Werk - wie das BVerfG erkennt - Wirkungen auf der sozialen Ebene (BVerfGE 30, 173, 193 f.). Das Interesse des bereits verstorbenen Schauspielers, von solchen sozialen Wirkungen, die von dem Kunstwerk ausgehen, verschont zu bleiben, ist verfassungsrechtlich durch das sog. postmortale Persönlichkeitsrecht abgesichert. Das BVerfG leitet es aus der Menschenwürdegarantie gemäß Art. 1 Abs. 1 GG $\mathrm{ab}$, nach dem „die Würde des Menschen unantastbar“ ist. Es wäre mit der Menschenwürde unvereinbar, ,,wenn der Mensch, dem Würde kraft seines Personseins zukommt, in diesem allgemeinen Achtungsanspruch auch nach seinem Tode herabgewürdigt oder erniedrigt werden dürfte" (BVerfGE 30, 173, 194). Die staatliche Schutzverpflichtung gilt also über den Tod des Einzelnen hinaus (Hufen 2011, $\S 101$ Rdnr. 106). 
Zur Beurteilung der Verfassungsmäßigkeit des Veröffentlichungsverbots bedurfte es einer Auflösung der Spannungslage zwischen Kunstfreiheit und postmortalem Persönlichkeitsrecht. Dabei betonte das BVerfG, dass keinem der Grundrechte abstrakt gesehen Vorrang zukomme, sondern eine „Abwägung aller Umstände des Einzelfalles“ erforderlich sei (BVerfGE 30, 173, 195; siehe auch Isensee 1993, 619, 628). Damit ist eine Abwägung der widerstreitenden Interessen gemeint. Was wiegt in dem Fall höher: das Interesse an der Veröffentlichung des Romans, sprich: die Freiheit künstlerischer Betätigung, oder das Interesse am Schutz des sozialen Geltungsanspruchs des Verstorbenen?

In dem in Rede stehenden Fall war zu berücksichtigen, „ob und inwieweit das Abbild gegenüber dem Urbild durch die künstlerische Gestaltung des Stoffs und seine Ein- und Unterordnung in den Gesamtorganismus des Kunstwerks so verselbständigt erscheint, daß das Individuelle, Persönlich-Intime zugunsten des Allgemeinen, Zeichenhaften der Figur objektiviert ist. Wenn eine solche, das Kunstspezifische berücksichtigende Betrachtung jedoch ergibt, daß der Künstler ein Porträt des Urbildes gezeichnet hat oder gar zeichnen wollte, kommt es auf das Ausmaß der künstlerischen Verfremdung oder den Umfang und die Bedeutung der Verfälschung für den Ruf des Betroffenen oder für sein Andenken an" (BVerfGE 30, 183, 195). Dem letzten Satz ist zu entnehmen, dass die Kunstfreiheit auch dann den Vorrang genießen kann, wenn es sich um ein ,verfälschendes Porträt" handelt, wobei dann der Grad der Schädlichkeit für den Ruf oder das Andenken der als Urbild fungierenden Person ausschlaggebend ist. Bei Personen der Zeitgeschichte spielt der Umstand eine Rolle, ob die Erinnerung des Publikums an die Person noch „lebendig“ ist (BVerfGE 30, 173, 196). Das Interesse an der Nichtverfälschung des Lebensbildes sinkt in dem Maße ab, in dem ,die Erinnerung an den Verstorbenen verblaßt" (BVerfGE 30, 173, 196). Die Übertragung dieses Maßstabs auf den konkreten Fall führt das BVerfG zu folgender Konstatierung: Das Abbild Höfgen erlange gegenüber dem Urbild Gründgens keine derartige Verselbständigung und sei in der Darstellung nicht derart „künstlerisch transzendiert“, dass das Individuelle eine hinreichende Objektivierung erfahre (BVerfGE 30, 173, 198). Diesen Schluss stützt das BVerfG darauf, dass ,zahlreiche Einzelheiten des Lebenslaufs und des äußeren Erscheinungsbildes“ von Höfgen und Gründgens einander weitgehend gleichkommen würden, weshalb „ein nicht unbedeutender Leserkreis unschwer in Höfgen Gründgens wiedererkenne“ (BVerfGE 30, 173, 198). Da diesem gegenüber dem Urbild nicht hinreichend objektivierten Abbild ein ,grundlegend negatives Persönlichkeits- und Charakterbild" angelastet worden sei, falle die Interessenabwägung zugunsten des Persönlichkeitsschutzes aus. Der Gedanke, welcher der Interessenabwägung durch das BVerfG im konkreten Fall vorschwebt, lässt sich mit folgenden, bereits oben zitierten Worten Thomas Manns wiedergeben:

Die Beobachtung kann man ja machen, daß ein so sehr an die Wirklichkeit gebundenes Werk am gefährdetsten ist und gewissermaßen ratlos wird, wo es frei von ihr abweichen und sie 
verleugnen möchte. Da ist dann leicht nicht alles in Ordnung, manches ist mehr unrichtig als frei und manches sogar nicht recht - so kommt es uns vor (Mann 1991, S. 273).

Der Entscheidung der Mehrheit der Richter des BVerfG trat Richter Stein mit seiner ablehnenden Meinung entgegen. Seiner Auffassung nach haben die Gerichte nicht hinreichend berücksichtigt, dass „ein Kunstwerk [...] Realität nicht nur im außerkünstlerischen Wirkbereich, sondern vorwiegend auf der ästhetischen Ebene besitzt" (BVerfGE 30, 173, 203). Der Einwand Steins lässt sich dahingehend zusammenfassen, die Gerichte hätten nur dem ,Spannungsfeld im sozialen Wirkbereich“ Rechnung getragen und „die ästhetische Realität des Romans“ ignoriert (BVerfGE 30, 173, 203). Der Roman sei nämlich „einseitig“ betrachtet worden, und zwar aus der Perspektive des Publikums und seiner Assoziationen. Zu beanstanden ist nach Stein, dass die Gerichte bereits zur Feststellung der Gemeinsamkeiten des Protagonisten und des Schauspielers Gründgens ausschließlich auf die „reale Wirklichkeit“" zurückgreifen und die künstlerische Dimension ausblenden würden. Die Übereinstimmung zwischen Höfgen und Gründgens werde nämlich vom Standpunkt der sozialen Realität und des Leserkreises aus abgeleitet, ohne dass auf das Kunstspezifische des Schöpfens eingegangen werde. Auf diese Perspektive stütze sich der gerichtliche Einwand der ,fehlenden hinreichenden Verfremdung und Transzendierung“"(BVerfGE 30, 173, 203f.). Der Maßstab, den die Gerichte anlegen würden, sei - so Stein - für Dokumentationen oder Biographien angemessen, nicht jedoch für einen Roman, dessen künstlerisches Anliegen „,nicht eine wirklichkeitsgetreue, an der Wahrheit orientierte Schilderung historischer Begebenheiten zum Ziel [hat], sondern wesenhafte, anschauliche Gestaltung aufgrund der Einbildungskraft des Schriftstellers“ (BVerfGE 30, 173, 204). Der Roman Mephisto strebe in der Diktion Steins eine ,gegenüber der realen Wirklichkeit verselbständigte, wirklichere' Wirklichkeit an, in der die reale Wirklichkeit auf der ästhetischen Ebene in einem neuen Verhältnis zum Individuum bewußter erfahren wird“ (BVerfGE 30, 173, 204). Stein betrachtet die künstlerische Darstellung nicht am Maßstab der realen Gegebenheiten, sondern an einem „kunstspezifischen, ästhetischen Maßstab“. Für ihn genügt die Übereinstimmung zwischen Höfgen und Gründgens nicht, um ein Verbot zu rechtfertigen. Denn diese Übereinstimmung werde gerade einseitig auf der Wirkungsebene festgestellt. Bei einer solchen Betrachtung sei zu befürchten, dass sich die ästhetische Ebene, die der werkbezogenen Ebene zuzuordnen sei, dem Publikum nicht erschließe. Würde man jede Verwendung von persönlichkeitsrelevanten Daten untersagen wollen, weil nicht auszuschließen wäre, dass die Leser das Werk unter Missachtung seiner künstlerischen Dimension einseitig anhand der realen Umstände verstehen und ihm so eine negative Darstellung einer faktisch existierenden Person als Urbild entnehmen würden, könnte die Kunst „eine ihrer wichtigsten Aufgaben nicht erfüllen“ (BVerfGE 30, 173, 206). Stein erachtet es daher als zulässig, künstlerische Darstellungen ,an eine Person der Zeitgeschichte“ anzulehnen und 
„Persönlichkeitsdaten aus der Wirklichkeit [...] verallgemeinernde Bedeutung zu geben“" (BVerfGE 30, 173, 206f.). Weiter unterstreicht er in dem Sondervotum, dass es sonst durchaus üblich ist, „Personen der Wirklichkeit“ in der einen und anderen Form in künstlerische Darstellungen einzubeziehen. Nicht ohne Bedeutung soll schließlich die Bemerkung des Autors bleiben, er wolle nicht die Geschichte eines bestimmten Menschen erzählen.

Dem Künstler müsse es möglich sein, ,zu zeitgenössischen Konflikten auf moralischem, gesellschaftlichem und politischem Gebiet" Stellung zu nehmen. Der Ausschluss gewisser Themen oder Darstellungsmethoden würde mit Art. 5 Abs. 3 GG in Konflikt geraten. Auch könne dem Künstler eine Verfremdung von Persönlichkeitsdaten, die Rückschlüsse auf eine konkrete Person ermöglichen würden, nicht abverlangt werden (BVerfGE 30, 173, 209). Vor diesem Hintergrund gelangt Stein zu der Schlussfolgerung, dass „Höfgen [...] als Romanfigur [...] und als Typ gegenüber dem Persönlichkeitsbild von Gustaf Gründgens verselbständigt [ist]“ (BVerfGE 30, 173, 211). Obwohl „Gründgens sehr deutlich der Romanfigur Höfgen zum Vorbild gedient hat" (BVerfGE 30, 173, 212), ist für Stein entscheidend, dass die Romanfigur nicht Individuelles über Gründgens bekanntmachen will, sondern eine selbständige Rolle übernimmt, die sie von Gründgens merklich distanziert. Die in die Beurteilung mit einzubeziehenden gesellschaftlichen und politischen Umstände der Zeit der Entstehung des Romans verdeutlichen Stein zufolge, dass es Klaus Mann darum ging, ,in anschaulicher Gestaltung das Phänomen des geistigen Mitläufertums im NS-Staat darzustellen“ (BVerfGE 30, 173, 213).

Auch was die Rechte von Gründgens betrifft, behauptet Stein, die Gerichte hätten ,die nachteiligen Wirkungen des Romans auf den Schutzbereich der Persönlichkeit von Gustaf Gründgens ... überbetont" (BVerfGE 30, 173, 214). Die Veröffentlichung des Romans müsste einen „besonders qualifizierten Eingriff in die Persönlichkeitssphäre" (BVerfGE 30, 173, 214) von Gründgens nach sich gezogen haben. Im Sinne der bereits oben angedeuteten Je-Desto-Formel hänge der Grad der gesellschaftlichen Auswirkungen auf die Person, die als Urbild gedient habe, davon ab, wie lange die Erinnerung an diese Person fortdauere, was sich wieder danach richte, wie groß das Interesse der Öffentlichkeit an dieser Person (gewesen) sei. Je schneller dieses Interesse sinke, desto geringer werde die Gefahr, dass es zu einer Wiedererkennung der realen Person hinter dem Protagonisten und mithin zu einer Verletzung des Persönlichkeitsrechts kommen werde.

Die Mehrheit des BVerfG schlug folgenden Weg ein: Überall dort, wo der Bezug der Romanfigur zu einer faktisch existenten Person aus Sicht der Allgemeinheit, ergo des Leserkreises, nicht zu leugnen ist, darf der Protagonist als Abbild dieser Person nicht um Merkmale oder Verhaltensweisen bereichert werden, die eine negative(-re) Bewertung der mit dem Protagonisten identifizierten Person zur Folge haben. Mit anderen Worten muss die künstlerische Darstellung der Wirklichkeit entsprechen, darf diese also nicht entstellen, wenn es an 
einer hinreichenden Fiktionalisierung fehlt. Wenn die Übereinstimmung nicht zu verkennen ist, muss die Abbildung treu sein. Demgegenüber setzt Stein andere Akzente. Dass die Allgemeinheit die Romanfigur mit einer echten Person in Verbindung bringt, reiche nach Stein nicht aus, um eine Verletzung des Persönlichkeitsrechts bejahen zu können. Eine solche einseitige Orientierung am sozialen Assoziationsmaßstab trage der künstlerisch-ästhetischen Ebene des Kunstwerkes nicht hinreichend Rechnung.

Am Rande sei zu bemerken, dass der Roman 1981 vom Rowohlt-Verlag veröffentlicht wurde. Die Veröffentlichung erfolgte trotz des BVerfG-Beschlusses nicht rechtswidrig, denn das Veröffentlichungsverbot der Gerichte und der Beschluss des BVerfG, mit dem die Verfassungsbeschwerde zurückgewiesen worden war, banden nur die Parteien des Rechtsstreits, also den Adoptivsohn und die Verlagshandlung, hatten demnach keine allgemeinverbindliche Wirkung gegenüber allen anderen Verlagen (siehe dazu Bünnigmann 2013, S. 73).

\section{Zusammenfassung}

Werden echte Personen in für die Leserschaft erkennbarer Weise zum Vorbild literarischer Figuren gemacht, besteht stets das Risiko, dass jede Modifizierung der fiktiven Figur die als Urbild dienende Person im neuen Licht erscheinen lässt. Der Konflikt ist evident. Im Roman Mephisto setzt sich Klaus Mann nicht nur mit der Kunstrealität im nationalsozialistischen Deutschland auseinander, sondern zugleich auch mit einem Menschentypus, der sich in die Umstände eines totalitären Regimes eingefügt hat. Dass dahinter eine wahre Person stand, die für die breite Leserschaft mit Gustaf Gründgens identifizierbar war, stand außer Zweifel. Mit welchem Ziel Klaus Mann den Romans schrieb, scheint aus literaturwissenschaftlicher Sicht zwar zweitrangig zu sein; ob er damit tatsächlich einen Racheakt auf seinen Ex-Schwager ausüben oder nur eine Gruppe von Mitläufern darstellen wollte, diese Fragen sind nur soweit wichtig, um die Intentionen des Autors zu verstehen, nicht aber den Sinn des Romans; doch gerade dieses Problem führte dazu, dass der Text zu einem der wichtigsten und bekanntesten Romane Klaus Manns wurde und bis heute diskutiert wird. Der im Beitrag skizzierte Weg des Schriftstellers von einem von der Politik distanzierten Autor, über seine Emigration und das immer ansteigende Engagement im Kampf gegen das NS-System versuchte aufzuzeigen, wie kompliziert es war, in den 1920er und 1930er Jahren eindeutige Positionen einzunehmen. Oft war es ein Prozess der Reifung nicht nur eines Schriftstellers, sondern auch eines Menschen, der sich in unterschiedlichen Formen des Protestes manifestierte. Diese Formen sind sowohl bei den Exilanten wie Inneren Emigranten gleichermaßen sichtbar. Um sie richtig zu erkennen und vor allem dementsprechend zu verstehen und im breiten geschichtlichen Kontext zu interpretieren, muss man stets zahlreiche Faktoren 
mitberücksichtigen, die zum Protest, zum Rückzug in die Innere Emigration oder zum Versagen geführt haben. Denn nicht nur Widerstand, egal in welcher Form auch immer, sondern auch eine gewisse Kollaboration waren genauso oft vorzufinden. Diejenigen, die es damals geschafft haben, die Gefahren zu bemerken und einzusehen, verdienen stets Respekt und Anerkennung. Klaus Mann verstand sein Schaffen als eine Mission, die darin bestand, die Welt über die sich aus dem Nationalsozialismus ergebenden Gefahren aufzuklären. In diesem Kontext tauchen sowohl die Auseinandersetzung Klaus Manns mit Gottfried Benn, als auch der Roman Mephisto als zwei nacheinander folgende Stufen derselben einerseits literaturkritischen/ästhetischen Diskussion zwischen zwei zeitgenössischen Schriftstellern, andererseits als Abrechnung zwischen Klaus Mann und einer konformistischen Stellung, die er am Beispiel mehrerer Protagonisten verewigt hat, auf. Der Zusammenhang zwischen ästhetischer und politischer Debatte ist hiermit nicht außer Acht zu lassen.

Und zum Schluss noch eine kurze juristische Ergänzung: Nun mögen die Akzente durch den Esra-Beschluss zugunsten der Kunstfreiheit verschieben worden sein. Das BVerfG stellte in der Entscheidung eine Vermutung der Fiktionalität auf, der zufolge bei Romanen grundsätzlich davon auszugehen ist, dass die Romanfiguren verselbständigt sind (BVerfGE 119, 1, 28 f.). Dies schließt es nicht aus, die Vermutung zu widerlegen, weshalb es nach wie vor auf eine Einzelfallbetrachtung ankommt.

\section{LITERATURVERZEICHNIS}

Benn G. (1977), Können Dichter die Welt verändern? In: Benn G., Autobiographische und vermischte Schriften, Wiesbaden/München, S. 213-222.

Brecht B. (1967), Schriften zum Theater 2. In: Gesammelte Werke, Bd. 16, Frankfurt/M.

Bünnigmann K. (2013), Die „Esra“-Entscheidung als Ausgleich zwischen Persönlichkeitsschutz und Kunstfreiheit, Tübingen.

Feuchtwanger L. (1950), In: Mann E. (Hrsg), Klaus Mann zum Gedächtnis, Amsterdam.

Gołaszewski M (2010), Erwin Stein - Mitgestalter des Landes Hessen, Mitgründer der Justus-Liebig-Universität Gießen, Humanist, Wissenschaftler, Politiker, Łódź.

Grunewald M. (1985), Klaus Mann und das politische Engagement. In: Mann K., Mit dem Blick nach Deutschland. Der Schriftsteller und das politische Engagement, München.

Harrison E.F. (1966), Death and Decadence in the Works of Klaus Mann. Innaugural-Dissertation zur Erlangung des Doktorgrades an der Harvard University, Cambridge/Mass.

Hufen F. (2011), Kunstfreiheit. In: Merten D., Papier H.-J. (Hrsg.), Handbuch der Grundrechte in Deutschland und Europa. Band IV Grundrechte in Deutschland. Einzelgrundrechte I, Heidelberg, $§ 101$.

Isensee J., Kunstfreiheit im Streit mit Persönlichkeitsschutz. In: AfP 1993, S. 619-629.

Kerker A. (1974), Ernst Jünger - Klaus Mann. Gemeinsamkeit und Gegensatz in Literatur und Politik, Bonn.

Kerker E. (1977), Weltbürgertum - Exil - Heimatlosigkeit. Die Entwicklung der politischen Dimension im Werk Klaus Manns von 1924-1936, Meisenheim am Glan. 
Kesten H. (1959), Klaus Mann. In: Kesten H. (Hrsg.), Meine Freunde, die Poeten, München, S. $411-422$.

Kingreen T., Poscher R., Pieroth B., Schlink B. (2013), Grundrechte. Staatsrecht II, Heidelberg u.a.

Kroll F. (1973), Klaus Mann und die Synthese von Moral und Schönheit. Einführung in das Frühwerk. Innaugural-Dissertation zur Erlangung des Doktorgrades an der University of Richester, Rochester/New York.

Kroll F. (1991), Warum ist Klaus Manns Mephisto so umstritten? In: Asper H.G., Wenn wir von gestern reden, sprechen wir über heute und morgen. Festschrift für Marta Mierendorff zum 80. Geburtstag, Berlin/Bonn, S. 219-230.

Laemmle P. (1989), Nachwort. In: Mann K., Tagebücher 1931-1933, München, S. 189-207.

Laemmle P. (1990), Nachwort. In: Mann K., Tagebücher 1936-1937, München, S. 181-190.

Kühl R. (1987), Der deutsche Faschismus in Quellen und Dokumenten, Köln.

Landshoff F. H. (1991), Amsterdam, Keizersgracht 333. Querido Verlag. Erinnerungen eines Verlegers, Berlin/Weimar. Lohmeier A.-M. (1987), Es ist doch ein sehr privates Buch. Über Klaus Manns Mephisto, Gustaf Gründgens und die Nachgeborenen. In: Arnold H. L. (Hrsg.), Klaus Mann. Text+Kritik, München, S. 100-128.

Maltzan C. (2001), Masochismus und Macht. Eine kritische Untersuchung am Beispiel von Klaus Manns ,,Mephisto. Roman einer Karriere“, Stuttgart.

Mann K. (1931), Heute und Morgen - Zur Situation des jungen geistigen Europas 1929. In: Mann K., Auf der Suche nach einem Weg, Berlin.

Mann K. (1931a), Wie wollen wir unsere Zukunft? In: Mann K., Auf der Suche nach einem Weg, Berlin.

Mann K. (1931b), Jugend und Paneuropa. In: Mann K., Auf der Suche nach einem Weg, Berlin.

Mann K., (1968), Prüfungen, München.

Mann K., (1973), Mephisto. Karriere eines Romans, Zürich.

Mann K. (1984), Der Wendepunkt. Ein Lebensbericht, Hamburg.

Mann K. (1986), Kind dieser Zeit, Hamburg.

Mann, K. (1989), Der fromme Tanz, Hamburg.

Mann, K. (1991), Briefe und Antworten: 1922-1949, Hamburg.

Mann T. (1950), Vorwort. In: Klaus Mann zum Gedächtnis, Amsterdam.

Manssen G. (2015), Staatsrecht II. Grundrechte, München.

Naumann U. (1984), Klaus Mann, Hamburg 1984.

Pasche W. (2000), Interpretationshilfen. Exilromane, Stuttgart/Düsseldorf/Leipzig.

Reich-Ranicki M. (1977), Klaus Mann, der dreifach Geschlagene. In: Reich-Ranicki M. (Hrsg.), Nachprüfung. Aufsätze über deutsche Schriftsteller von gestern, München.

Sachs M. (2003), Verfassungsrecht II. Grundrechte, München.

Schiller D. (1983), Geistige Differenz und politische Disziplin. In: Schlenstedt S. (Hrsg.), Wer schreibt, handelt. Berlin/Weimar, S. 163-198.

Schmidt A. (2003), Exilwelten der 30er Jahre. Untersuchungen zu Klaus Manns Emigrationsromanen Flucht in den Norden und Der Vulkan. Roman unter Emigranten. Würzburg.

Schneider R. (1956), Klaus Mann, In: Aufbau (12), Dezember, S. 1105-1119.

Scholz R. (2014), Art. 5 Abs. 3, In: Maunz T., Dürig G. (Hrsg.), Grundgesetz. Kommentar.

Spangenberg E. (1984), Karriere eines Romans. Mephisto, Klaus Mann und Gustaf Grüdgens. Ein dokumentarischer Bericht aus Deutschland und dem Exil 1925-1981. Mit 151 Abbildungen, München 1984.

Strich F. (1960), Klaus Mann. In: Strich F. (Hrsg.), Kunst und Leben, Bern, S. 191-200.

Walter H.-A. (1965), Der Mitläufer. „Mephisto“ - Klaus Manns großer Roman über den Verrat am Geist während der Nazi-Herrschaft, In: Frankfurter Allgemeine Zeitung, Nr. 272, v. 23.11.

Walter H.-A. (1966), Das Bild Deutschlands im Exilroman, In: Die Rundschau, Nr. 77, S. 437-458. 
Walter H.-A. (1966), Der engagierte Ästhet, In: Frankfurter Allgemeine Zeitung v. 18.11.

Weil B. (1983), Klaus Mann: Leben und literarisches Werk im Exil, Frankfurt/M.

Winckler L. (1983), Klaus Mann: Mephisto. In: Exilforschung, Bd. 1, München.

Winckler L. (1984), „... ein richtig gemeines Buch, voll von Tücken “. Klaus Manns Romans Mephisto, In: Wolff R. (Hrsg.), Klaus Mann. Werk und Wirkung, Bonn, S. 46-80.

Winckler L. (1987), Artist und Aktivist. In: Arnold H. L. (Hrsg.), Klaus Mann, München, S. 73-87.

\author{
Marcin Gołaszewski \\ Dawid Ligocki
}

\title{
„EIN SCHRIFTSTELLER, DER POLITISCHE GEGENSTÄNDE IN SEIN KÜNSTLERISCHES SCHAFFEN EINBEZIEHEN WILL, MUSS AN DER POLITIK \\ GELITTEN HABEN“. KLAUS MANN AND THE POLITICS. MEPHISTO - CAREER OF A NOVEL OR A NOVEL OF CAREER
}

(Summary)

The novel Mephisto is one of the most well-known texts by Klaus Mann. Its fame results not only from its literary virtuosity, but also and primarily from the enormous media attention which was caused by the novel's publication. The decision of the Federal Constitutional Court, in which it dealt with the relationship between freedom of art and other constitutionally guaranteed rights of individuals, launched the unprecedented career of this novel. This article describes Klaus Mann's political views and their development in the 1920s during the time when the National Socialist movement was strengthening and the writer made the decision to emigrate. The essay deals with the circumstances of creating the novel considering both biographical and political issues. The novelist is described from the perspective of the reality of the 1930s during the National Socialist regime and the time after his emigration. The concern of the article is not a literary analysis of the novel, but to take a look at the novelist's development up until the moment of finishing his work as a protest against National Socialism. Another goal of the essay is to analyze the decision of the Federal Constitutional Court, which regards the balance between freedom of art and other basic rights. Considering the synergy of both methodological approaches and the interdisciplinary view on the problem, the article represents a novel attempt to give a complex view on the relationship between art (literature) and the reality of a totalitarian state and between the relationship art-state in the conditions of a democratic state.

Key words: The 3rd Reich, irrationalism, Klaus Mann, exile, Mephisto, Gottfried Benn, freedom of art. 